pragMATIZES - Revista Latino Americana de Estudos em Cultura

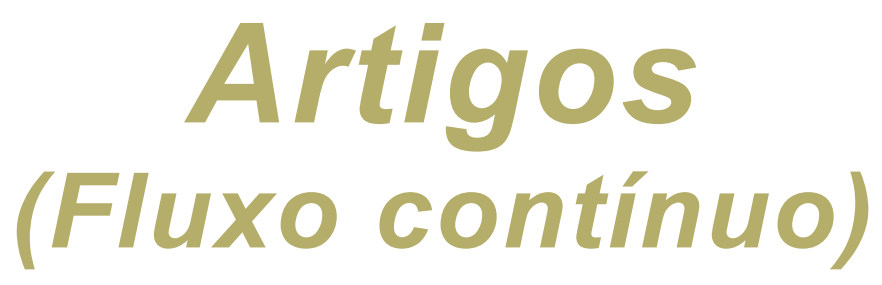

Disponível em http://periodicos.uff. br/pragmatizes 


\title{
Fundamentos teóricos e metodológicos de tratamento informacional de documentos de análises físico-químicas aplicadas a objetos do patrimônio cultural ${ }^{1}$
}

\author{
Fundamentos teóricos y metodológicos de tratamiento \\ de la información de documentos de análisis físico-químicos \\ aplicados a objetos del patrimonio cultural
}

\begin{abstract}
Theoretical and methodological foundations of informational processing of physical-chemical analysis documents applied to objects of cultural heritage
\end{abstract}

\author{
Nair Yumiko Kobashi \\ Laís de Oliveira ${ }^{3}$
}

\begin{abstract}
Resumo:
Palavras-chave:

Organização

da informação

Representação

da informação

Imagens científicas

Curadoria digital

Metadados

Estudo dos fundamentos teóricos e metodológicos de tratamento informacional da documentação produzida por análises físico-químicas aplicadas a objetos do patrimônio cultural. Essas técnicas geram imagens e gráficos decorrentes da interação de radiação eletromagnética com a matéria dos objetos e permitem identificar materiais, técnicas, processos, origem, intervenções realizadas, autenticidade das obras, etc. Procurouse destacar as características e atributos para descrever a documentação estudada, relacioná-la aos objetos analisados, organizar, representar e armazená-los em um sistema de informação. Foi inicialmente realizada uma revisão bibliográfica para: (a) compreender e definir o gênero documental e o tipo de documentação produzido pelas técnicas arqueométricas; (b) estudar um sistema de recuperação de informação, cujos aspectos centrais são a estrutura de metadados e a terminologia a ser empregada; (c) conhecer métodos para gerir, manter, preservar e recuperar dados de pesquisas de aplicação de métodos físico-químicos. Espera-se, ao final da pesquisa, sistematizar os parâmetros de construção de repositórios digitais para armazenar, organizar e disponibilizar esta documentação, contribuir para aumentar a visibilidade dos acervos dos museus da USP e promover melhor acesso às pesquisas sobre o patrimônio cultural.
\end{abstract}

\footnotetext{
1 Texto recebido em 10/12/2018 e aceito para publicação em 24/10/2019.

2 Nair Yumiko Kobashi. Docente junto ao Programa de Pós-Graduação em Ciência da Informação da Universidade de São Paulo. Pesquisadora 1D do CNPq, Brasil. Contato: nairkobashi@gmail.com - https://orcid.org/0000-0002-5282-7363 


\section{Resumen:}

Estudio de los fundamentos teóricos y metodológicos de tratamiento de la información de documentos producidos por análisis físico-químicos aplicadosa objetos del patrimonio cultural. Estastécnicas generanimágenes y gráficos resultantes de la interacción de radiación electromagnética con la materia de los objetos y permiten identificar materiales, técnicas, procesos, origen, intervenciones realizadas, autenticidad de las obras etc. Se buscó destacar las características y atributos para describir la documentación estudiada, relacionarla con los objetos analizados, organizar, representar y almacenarlos en un sistema de información. Se realizó inicialmente una revisión bibliográfica para: (a) comprender y definir el género documental y el tipo de documentación producida por las técnicas arqueométricas; (b) estudiar un sistema de recuperación de información, cuyos aspectos centrales son la estructura de metadatos y la terminología a aplicar; (c) conocer métodos para gestionar, mantener, preservar y recuperar datos de investigaciones de aplicación de métodos físico-químicos. Se espera, al final de la investigación, sistematizar los parámetros de construcción de repositorios digitales para almacenar, organizar y poner a disposición esta documentación, contribuir a aumentar la visibilidad de los acervos de los museos de la USP y promover un mejor acceso a las investigaciones sobre el patrimonio cultural.

\section{Palabras clave:}

Organización de la información

Representación de la información

Imágenes científicas

Curaduría digital

Metadados

\section{Keywords:}

Information organization

Information representation

Scientific images

Digital curation

Metadata

\section{Abstract:}

Study of the theoretical and methodological foundations of informational treatment of documentation that is the product of physico-chemical analysis applied to objects of cultural heritage. These techniques generate images and graphs resulting from the interaction of electromagnetic radiation with the matter of objects and allow to identify materials, techniques, processes, origin, interventions performed, authenticity of works, etc. It was sought to highlight the characteristics and attributes to describe the documentation studied, to relate it to the objects analyzed, to organize, to represent and to store them in an information system. Initially, a bibliographic review was carried out to: (a) understand and define the documentary genre and the type of documentation produced by the arqueométricas techniques; (b) to study an information retrieval system, whose central aspects are the metadata structure and the terminology to be used; (c) to identify methods for managing, maintaining, preserving and retrieving research data on the application of physicochemical methods. At the end of the research it is expected to systematize the construction parameters to create a digital repository to store, organize and make available this documentation, in order to contribute to increase the visibility of the collections of USP museums and to promote better access to research on cultural heritage. 


\section{Fundamentos teóricos e metodológicos de tratamento informacional de documentos de análises físico-químicas aplicadas a objetos do patrimônio cultural}

\section{Introdução}

Esta pesquisa, que se encontra em desenvolvimento, tem como objetivo buscar fundamentos teóricos e metodológicos de tratamento informacional da documentação produzida por análises físico-químicas aplicadas a objetos do patrimônio cultural. Essas técnicas, geram imagens e gráficos decorrentes da interação de radiação eletromagnética com a matéria dos objetos e permitem identificar materiais, técnicas, processos, origem, intervenções realizadas, autenticidade das obras. Possibilitam, desse modo, detetar informações que não são perceptíveis a olho nu.

Empregadas desde o século XVIII em museus, essas técnicas tornaram-se mais comuns a partir do século XX. No Brasil, são recentes as pesquisas teóricas sobre as técnicas de análises físico-químicas de objetos de acervos museológicos. Um importante centro de pesquisas sobre o tema é o Núcleo de Apoio à pesquisa de Física Aplicada ao Estudo do Patrimônio Artístico e Histórico - NAP-FAEPAH, criado em 2012, especificamente para o estudo do patrimônio cultural dos museus da Universidade de São Paulo.

Atualmente, a documentação gerada nesses experimentos laboratoriais, constituída de relatórios e artigos acadêmicos, encontra-se dispersa, sendo de difícil acesso para consulta. Internacionalmente, foi identificado um único projeto dessa natureza: o APPEAR project, do Getty Museum, previsto para lançamento em 2018 (GETTY MUSEUM, 2013).
O projeto em andamento nasceu dos seguintes questionamentos: (a) Como relacionar a documentação gerada pelos experimentos com os objetos analisados? (b) Como organizar e representar essa documentação e armazená-la em um sistema de recuperação de informação? (c) Quais características e atributos dessa documentação podem ser descritos de forma sistemática e padronizadas? Já existem padrões elaborados para esta finalidade?

Decorrem do objetivo geral os seguintes objetivos específicos: (a) analisar as técnicas físico-químicas para identificar suas características e elementos a fim de sistematizá-las em um padrão de metadados de descrição; (b) sistematizar as teorias de análise de imagens específicas para a documentação estudada, a fim de encontrar diretrizes para a sua análise e descrição; (c) analisar as tecnologias que permitam elaborar repositórios desses tipos de documentos, em consonância com as necessidades dos usuários dessa documentação.

Espera-se, ao final da pesquisa, sistematizar os parâmetros de construção de repositórios digitais para armazenar, organizar e disponibilizar esta documentação, contribuir para aumentar a visibilidade dos acervos dos museus da USP e promover melhor acesso às pesquisas sobre o patrimônio cultural.

\section{Metodologia}

$\mathrm{Na}$ etapa inicial da pesquisa, foi realizada uma revisão bibliográfica que permitiu: a) compreender e definir o gênero documental e o tipo de documentação produzido pelas técnicas arqueométricas; b) estudar modelos de representação conceitual para descrição de documentação iconográfica; c) estudar um sistema de recuperação de informação, cujos aspectos 
centrais são a estrutura de metadados e a terminologia a ser empregada; d) conhecer métodos para gerir, manter, preservar e recuperar dados de pesquisas de aplicação de métodos físico-químicos.

Para a parametrização do sistema de recuperação foram analisadas diferentes propostas de estruturação de metadados, cujos constituintes mais importantes são: identificação e descrição da informação; b) busca e recuperação; c) localização e formas de acesso; d) atualização da informação; e) preservação e conservação; f) definição de níveis de acesso; g) valorização do conteúdo; h) visibilidade da informação; i) acessibilidade ao conteúdo (RODRIGUEZ, 2002).

Dentre os modelos de metadados, o que melhor responde aos objetivos da presente pesquisa é o proposto por Gilliand (2016), que considera os seguintes atributos: a) administrativos (responsabilidade e a data de realização da análise; b) descritivos (técnicas aplicadas e tipos de documentos gerados; c) de preservação (estado físico da obra original); d) técnico (técnicas utilizadas); e) de uso (níveis de acesso de usuários).

\section{Referencial teórico: \\ Técnicas de análise de imagens}

Como exposto na Introdução, a documentação estudada é composta de imagens e gráficos gerados pela interação de radiação eletromagnética com a matéria dos objetos. As técnicas de obtenção destas imagens são semelhantes às técnicas fotográficas, porém com comprimento de ondas diferentes da luz visível. Os métodos de análise envolvem dois tipos de processos: exames visuais que geram imagens como produto do diagnóstico e técnicas de análise elementar e composicional de materiais, que geram espectros característicos das técnicas utilizadas em forma de gráficos.

Os exames visuais "baseiam-se em processos de interação da radiação eletromagnética com a matéria pictórica" (RIZZUTTO; KAJIYA; CAMPOS, s/d), cujos resultados, observados durante os processos, são capturadas por uma câmera fotográfica, ou equipamento específico, para serem documentados.

Esses tipos de documentos iconográficos têm desempenhado uma função importante, tanto para examinar como para documentar o estado de conservação da obra de arte (RIZZUTTO, 2015). Cada técnica apresenta, individualmente, dados particulares capazes de identificar informações específicas sobre a obra. Com a combinação de todas estas técnicas de imageamento "podem-se obter informações correlacionadas que permitem melhor caracterizar o objeto em estudo" (RIZZUTTO; KAJIYA; CAMPOS, s/d). As técnicas de imageamento empregadas são apresentadas a seguir.

\subsection{Imagem com Luz Visível}

Esta técnica consiste em iluminar a obra com luz visível, entre o comprimento de onda de 400 a $780 \mathrm{~nm}$, utilizando lâmpadas de halogênio ou de tungstênio, juntamente com uma tabela de cor. Isso permite obter o registro preciso da cor e do estado aparente de conservação da obra (RIZZUTTO, 2015). O resultado gerado pode ser capturado por uma câmera fotográfica digital com sensor CCD, e filtros acoplados à lente.

Os dados relevantes que foram observados nesta técnica, a fim de registro, são: (a) tipo de técnica empregado; (b) tipo de documento produzido; (c) o tipo e características da fonte utilizada; (d) data de realização da análise; (e) responsá- 
vel, indicando o laboratório ou técnico; (f) dados do equipamento do registro (câmera), como, por exemplo, ISO, tempo do obturador, etc. No caso das câmeras digitais, os dados são automaticamente registrados pela câmera como metadado do arquivo.

\subsection{Imagem com Luz Rasante ou oblíqua}

A obra é iluminada com uma fonte de luz que incide de forma tangencial em relação à superfície da pintura. Isso "permite observar irregularidades e movimentos do suporte e da camada cromática" (NAP-FAEPAH, s/d.) que não poderiam ser vistas a olho nu, tal como a presença de fungos, craquelamento e fissuras na policromia e áreas retocadas (RIZZUTTO; KAJIYA; CAMPOS, s/d).

Os dados observados são semeIhantes aos obtidos com a técnica de Imagem com Luz Visível, (itens a a f). Porém, esta técnica revela informações complementares sobre o suporte e sobre o material cromático, levando à necessidade da criação de um campo (g) para a descrição dessas informações.

\subsection{Imagem de Fluorescência vi- sível com radiação de ultravioleta (UV)}

Nesta técnica, utiliza-se uma fonte de iluminação de radiação ultravioleta entre os comprimentos de onda de 340 a $400 \mathrm{~nm}$ (RIZZUTTO, 2015), que incide na obra e excita o material. Este emite uma radiação fluorescente do material que, manifestando-se na forma de luz visível, pode ser capturada pelo equipamento fotográfico. Com este procedimento, podem ser observadas as intervenções ou restauros sofridos pela obra, de modo a registrar o estado de conservação atual da obra. Os dados a serem observados nesta técnica são os mesmos da técnica apresentada nos itens 3.1 e 3.2.

\subsection{Reflectografia de Infraverme- Iho (IR)}

Nesta técnica, a obra é iluminada com duas lâmpadas de halógenos de $3200 \mathrm{~K}$ de $1.000 \mathrm{~W}$, que possuem comprimento de onda entre 400 a $900 \mathrm{~nm}$ e ângulo de incidência de $45^{\circ}$. O resultado do processo de reflectância de luz infravermelha com o material, composto de carbono ou grafite, deve ser registrado com uma câmera digital de alta resolução operando entre a faixa do espectro de IR. Com esta técnica é possível observar os primeiros traços do artista feitos a carvão ou grafite, áreas que sofreram intervenções e alterações. Os dados a serem observados nesta técnica são os mesmos das técnicas apresentadas nos itens 3.1 e 3.2 .

\subsection{Radiografia de Raio-X}

$\mathrm{Na}$ técnica, a obra é irradiada com feixes de Raio-X. Os materiais, ao serem atravessados pela radiação $X$, comportam-se de forma específica, apresentando diferentes graus de opacidade que variam de acordo com a espessura, massa específica do material e sua natureza química. O resultado é uma imagem em tons de cinza registrada digitalmente por um detector do tipo "Image Plate", que capta a imagem gerada, por meio de um scanner especial, que a converte em sinal digital.

Este diagnóstico auxilia na avaliação do estado de conservação da obra, revelando características como: "estrutura do objeto, pinturas subjacentes, alterações e danos (emendas, recortes, etc.), localização de pregos, cravos e em alguns casos identificação do processo de montagem da obra" (NAP-FAEPAH, s/d.).

Os dados a serem observados nesta técnica são os mesmos da técnica apresentada no item 3.2. 


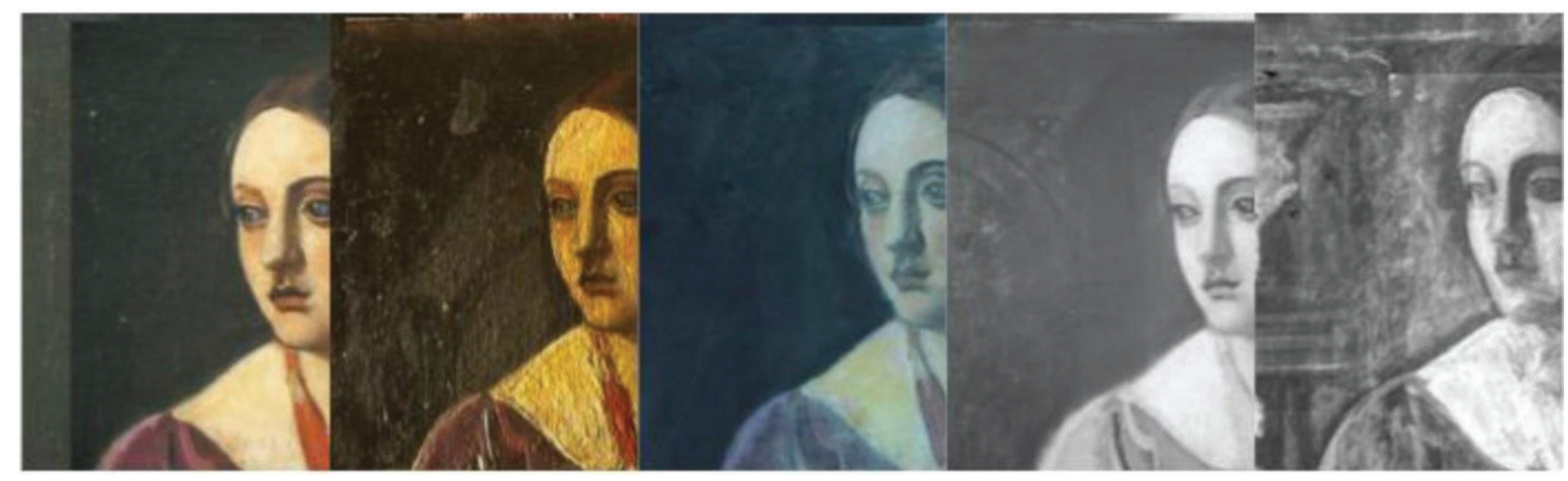

Figura 1: Exemplo dos resultados de técnicas de exames visuais na obra Advinha (1924) de Achille Funi (1890-1972)

Da esquerda para a direita: (a) imagem de luz visível; (b) imagem de luz rasante; (c) imagem de ultravioleta; (d) imagem de infravermelho; (e) imagem de raio X. Pintura original: óleo sobre madeira. Coleção Francisco Matarazzo Sobrinho - MAC USP. Fotos: Elizabeth Kajiya

Fonte: NAP-FAEPAH, 2014. Montagem fotográfica própria.

As técnicas de análise elementar e composicional de materiais, empregadas para identificar os elementos químicos e composição de materiais orgânicos e inorgânicos que compõem, ou estejam presentes na obra estão apresentadas a seguir.

\section{(EDXRF) \\ 3.6. Fluorescência de raios $X$}

Consiste em irradiar uma obra com uma fonte de raio- $X$, ou de raio gama, que irá interagir com os elétrons orbitais dos átomos do material analisado, excitando o átomo que, no seu decaimento, emite raios $X$ característicos do material existente no objeto estudado (RIZZUTTO; KAJIYA; CAMPOS, s/d.) que são capturados por um detector. Os resultados obtidos são gerados em forma de gráficos nos quais podem ser identificados os elementos químicos presentes na amostra utilizada (RIZZUTTO; KAJIYA; CAMPOS, s/d.).

Os dados observados são: (a) tipo de técnica empregado; (b) tipo de documento produzido; (c) tipo e características da fonte utilizada; (d) data de realização da análise; (e) responsável, indicando o laboratório ou técnico; (f) dados do equipamento do detector (como o seu modelo, potência e precisão). Neste caso, o resultado da análise é pontual e, portanto, deve ser indicado, gerando uma segunda documentação, que é uma imagem de mapeamento da obra.

\subsection{Emissão Induzida de Radia- ção X por partículas (PIXE)}

Consiste em irradiar uma amostra com um feixe de íons capaz de atingir camadas eletrônicas internas da superfície do material analisado (TABACNIKS, s/d., p. 9), o que acaba emitindo raios $X$ com energia característica e a detecção da radiação permite identificar a composição atômica do alvo (RIZZUTTO, 2008) e examinar pigmentos de pinturas. Os dados relevantes observados são idênticos ao do item 3.6. 


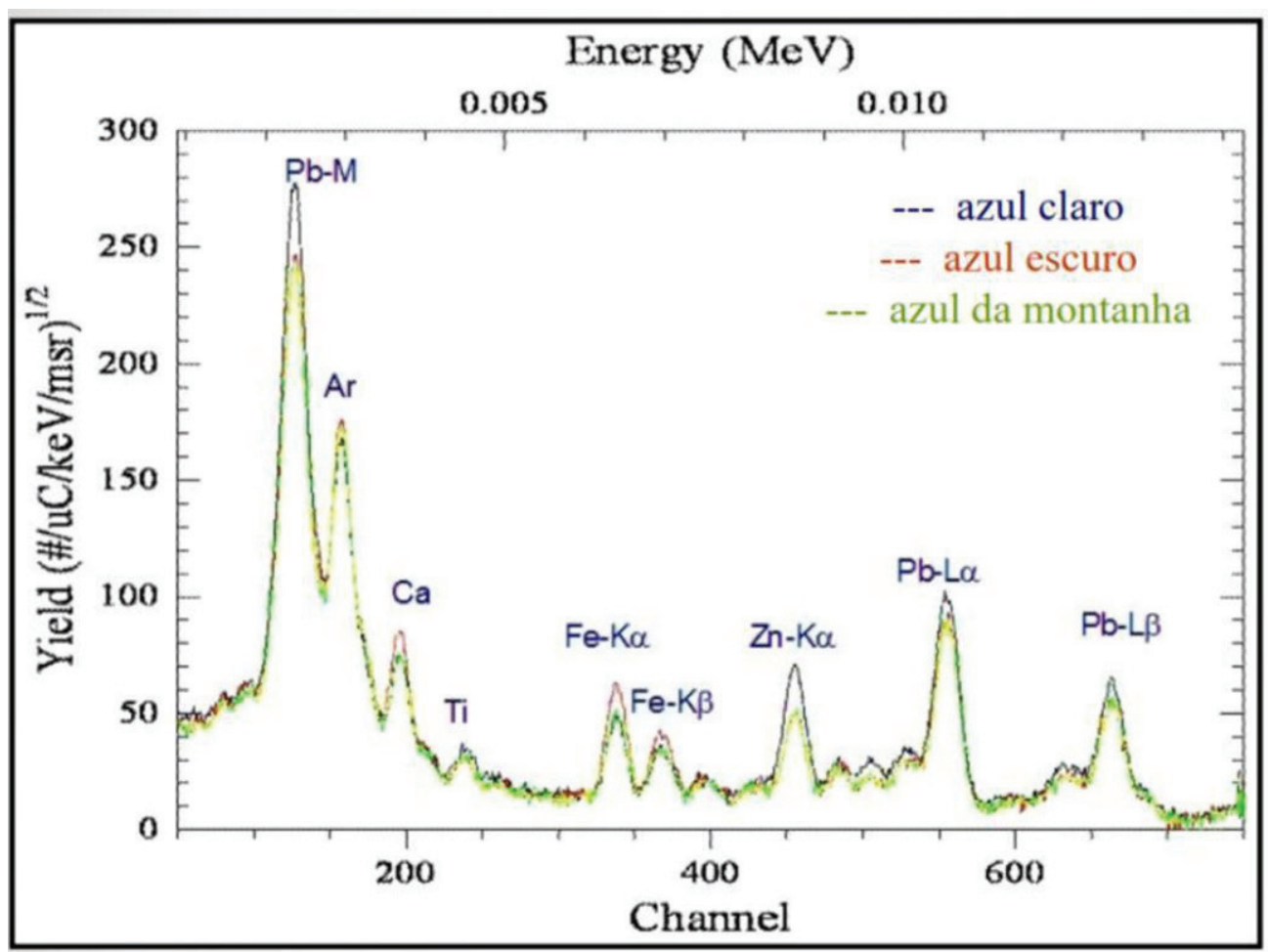

Figura 2: Gráfico resultado de análise PIXE aplicado a uma Obra Não identificada.

Foto: Paulo Pascholati.

Fonte: Aula de Física aplicada ao estudo de objetos do Patrimônio Cultural: métodos e técnicas, da Profa. Dra. Márcia A. Rizzutto, Programa de Pós-graduação Interunidades em Museologia da Universidade de São Paulo.

\subsection{Emissão Induzida de Radia- ção gama por partículas (PIGE)}

Esta técnica consiste em irradiar com um feixe de íons um objeto, que faz com que o núcleo dos átomos se excite por meio de reações nucleares, emitindo raios y característicos (RIZZUTTO, 2008). Esse método é utilizado para detectar elementos químicos (LAMFI, 2009), analisar corrosões "e deste modo possibilitar aos restauradores o melhor procedimento para a conservação e restauração das peças em estudo" (RIZZUTTO, 2008, 213).

\subsection{Espalhamento Rutherford em ângulos traseiros (RBS)}

Baseia-se na detecção das partículas do feixe espalhadas pela amostra utilizada, após realizar uma colisão elástica
(LAMFI, 2009). Na perda de energia da partícula é possível obter informações de espessura e de perfil de profundidade (LAMFI, 2009), que resulta em um gráfico da intensidade (taxa de contagens) em função da energia das partículas detectadas. (TABACNIKS, s/d. p. 6).

Assim, por meio de técnicas científicas, é possível ter novos olhares sobre os objetos culturais e obter informações que não eram possíveis de serem obtidas a olho nu. Estas técnicas, também, chamadas de técnicas arqueométricas, permitem que cientistas, restauradores, conservadores, arqueólogos, historiadores, realizem diagnósticos precisos que revelam materiais e técnicas utilizados pelo artista, bem como desenhos subjacentes, intervenções de restauro e perícias de autenticidade da obra. 


\section{Referencial teórico: teorias de análi- se e recepção de imagens}

Para o tratamento formal da documentação objeto do presente estudo, procurou-se, também, definir teoricamente as unidades que as compõem. Para isso, partiu-se do conceito de imagem, já que as técnicas empregadas geram imagens e gráficos variados. Essas imagens são formadas por constantes formais e elementos semânticos, reunidos e registrados em um suporte. Podem, portanto, ser definidas como documentos. Neste caso, pode ser caracterizado como documento iconográfico, também chamado de documento visual (BACA, 2002), aquele que carrega informação iconográfica, ou seja, por meio da imagem, cuja "linguagem básica é a imagem" (BERNARDES et al., 2008, p. 16). Pode ser compreendido como:

Documento cuja principal característica é a representação de imagens num plano em duas dimensões ou, aparentemente, em três, reproduzidas graficamente; documento visual não acompanhado de som. Costuma dividir-se em duas categorias, conforme é de acesso direto (não projetável) ou o seu acesso necessita da utilização de aparelhagem de um determinado tipo (projetável). (FARIA; PERICÃO, 2008, p. 255)

No campo da Biblioteconomia, o código de catalogação Anglo-Americano - AACR2 (2005) - considera como documento iconográfico todo material gráfico, abrangendo documentos originais, ou reproduções projetáveis ou não. $\mathrm{Na}$ arquivologia, o documento iconográfico é aquele que possui "imagens fixas, impressas, desenhadas ou fotografadas, como fotografias e gravuras." (ARQUIVO NACIONAL, 2005, p. 76). Os autores Guinchat e Menou (1994) acrescentam ao conjunto dos documentos iconográficos os mapas, plantas, gráficos, tabelas, cartazes; e Baca (2002) acrescenta os slides e arquivos digitais.
Portanto, pelas definições acima, as imagens e os gráficos gerados pelas técnicas arqueométricas podem ser tomados como documentos iconográficos. Segundo Smit (2000), o documento iconográfico carrega um poder testemunhal, uma ligação íntima com o referente. Porém, essa característica depende de uma "disponibilidade de informações que permitirão entender a imagem" (SMIT, 2000, p. 75).

A questão que se segue é, como viabilizar a busca e recuperação desses tipos de documentos em um sistema de informação? Como se sabe, no âmbito da Ciência da informação, a construção de sistemas de informação requer a inscrição de dados em campos recuperáveis, ou seja, os campos contêm informações que representam os documentos.

A representação de conteúdo de documentos em um sistema de informação é feita por meio de códigos verbais, portanto, por meio de palavras. Como o documento iconográfico é constituído de um código não verbal é necessário, segundo Smit (2000), que ocorra uma 'tradução' da imagem para compor pontos de acesso. Para isso, é necessário dispor de métodos e ferramentas de análise e descrição de dados estruturados sob a forma de metadados.

Segundo Joly (2012), existem vários tipos de imagens, desde os que representam as coisas do mundo real; imagens científicas que capturam um instante de um dado fenômeno em estudo; imagens mentais; virtuais, etc. Há diversas formas de entender a imagem e o modelo de tratamento deve direcionar o processo de identificação e extração das informações. Deve-se observar que a aplicação direta das normas destinadas ao tratamento de documentos textuais nem sempre são adequadas para descrever documentos imagéticos.

As imagens abordadas na presente pesquisa são do tipo científico, pois se origi- 
nam a partir da aplicação de diferentes técnicas de interação de radiação eletromagnética com a matéria. Cada técnica gera uma imagem com características particulares, revelando informações sobre o documento que não seriam possíveis de serem identificadas a olho nu. Para entendê-las e 'traduzi-las' para integrarem um sistema de informação, é necessário buscar ferramentas de análise, neste caso, uma teoria de análise da imagem que ofereça parâmetros para a sua descrição consistente.

Para realizar a análise de uma imagem é necessário dominar a linguagem visual para compreender a sua mensagem (JOLY, 2012), isto é, deve-se considerar o processo de percepção e interpretação da imagem. Deve-se ser capaz de identificar tanto o contexto de produção, quanto o de recepção, deve-se ser capaz de "decifrar as significações que a 'naturalidade' aparente das mensagens visuais implicam" (JOLY, 2012, p. 43).

Identificar estes contextos não significa ser capaz de reconstituir as condições em que ela foi criada ou descobrir o que o artista quis dizer. Para realizar uma análise é preciso definir um objetivo, ferramentas e referências, "levar em conta a função dessa mensagem, seu horizonte de expectativas e seus diversos tipos de contexto" (JOLY, 2012, p. 68).

Portanto, é necessário ter um referencial teórico que permita fornecer instrumentos para a análise das imagens, compreender o contexto de produção e recepção das imagens científicas e dos gráficos. Há quatro teorias conhecidas para orientar a análise de imagens: a semiótica, a iconologia, a pragmática e a fenomenologia.

Resumidamente, a semiótica, Segundo Santaella (1983), pode ser aplicada a todas as formas de linguagens, desde a verbal como a de desenhos, danças, músicas, cerimoniais, jogos, arquitetura, linguagens binárias de máquinas e, até mesmo, à linguagem da natureza e aos sistemas biológicos. A semiótica pode ser definida como a "ciência que tem por objeto de investigação todas as linguagens possíveis, ou seja, que tem por objetivo o exame dos modos de constituição de todo e qualquer fenômeno como fenômeno de produção de significação e de sentido" (SANTAELLA, 1983, p. 2).

Ela teve três origens, segundo Santaella (1983), quase que simultâneas: norte-americana, cronologicamente a primeira, elaborada pelo cientista-lógico-filósofo Charles Sanders Peirce (1839-1914), cujo foco é o conhecimento; a europeia, conhecida como semiologia, criada por Ferdinand de Saussure (1857-1913), cujo foco é a linguística; e a soviética, elaborada por Alexander N. Viesselovski (1838-1906) e Alexander A. Potiebniá (1835-1891), considerada a raiz do estruturalismo linguístico soviético. A corrente de Charles Sanders Peirce, baseia todo o corpo teórico em tríades: na dialética afirmação-negação-incerteza; nos níveis sintático-semânticos: nome-proposição-inferência; e em raciocínios lógicos: dedução-indução-abdução.

Outra teoria importante na análise de imagens é a Iconologia, elaborada por Erwin Panofsky, apresentada na obra Estudos em Iconologia (PANOFSKY,1939). Esta teoria propõe uma forma de análise da imagem em três níveis de descrição: pré-iconográfica, iconográfica e iconológica.

A descrição pré-iconográfica $\left(1^{\circ}\right.$ nível) descreve os elementos em âmbito genérico. A descrição iconográfica $\left(2^{\circ}\right.$ nível) identifica, ou especifica os elementos, tais como nomes próprios, mitológicos, religiosos, históricos, ou conteúdos não narrativos em forma de pessoa, lugar ou coisa (BACA, 2002). São considerados do nível iconológico ( $3^{\circ}$ nível), a interpretação, a significação simbólica, ou o habitus:

Por intermédio da interpretação iconológica dos gestos, adquirimos "a impressão de que estes contêm modos específicos 
de existência [...] Habitus enquanto conceito pode referir-se tanto a fenômenos individuais quanto a fenômenos coletivos relativos ao meio social (milieu), por exemplo, o habitus proletário ou burguês [...] também exprimir um determinado período histórico ou uma geração. (BOHNSACK, 2007, p. 291-292, grifo do autor)

Seguindo esta teoria, é possível identificar os elementos de uma imagem nos seus vários níveis, podendo-se utilizar descritores genéricos, específicos até atingir a interpretação da imagem. Essa teoria é bastante empregada no campo das artes para analisar obras de arte e realizar o seu tratamento temático. Por outro lado, as informações reveladas pelas técnicas de infravermelho e radiografia de raio- $X$ podem contribuir com informações relevantes para a análise da obra, principalmente no terceiro nível, porém as outras técnicas revelam informações de outras naturezas que não se enquadram dentro dessa teoria.

A fenomenologia, outra importante concepção de análise de objetos, pode ser resumidamente definida como o estudo ou a ciência dos fenômenos (BACA, 2002). Edmund Husserl (1859-1938) acreditava que nós compreendemos os fenômenos por intermédio dos sentidos, que são captados e interpretados pela consciência, sendo esta última responsável por reconhecer a si e ao mundo (DARTIGUES, 1992). Nessa análise, o mundo não é uma existência, mas um fenômeno. Maurice Merleau-Ponty (1908 - 1961), aprofundou-se na questão da percepção, em que o homem e sua consciência possuem vínculos indissociáveis com o espaço e o tempo. Nessa medida, "O homem está antes dele no mundo e é no mundo que ele conhece a si mesmo" (MERLEAU-PONTY; BANNAN,1956, p. 62, tradução livre). Por sua vez, "o mundo está sempre 'lá' como uma presença inalienável que precede a reflexão" (MERLEAU-PONTY; BANNAN, 1956, p. 59, tradução livre).
Assim, Merleau-Ponty e Bannan (1956) definem a fenomenologia como "o estudo das essências e, consequentemente, o tratamento de cada problema é uma tentação de definir uma essência, a essência da percepção ou a essência da consciência" (MERLEAU-PONTY; BANNAN,1956, p. 59, tradução livre). A princípio, considerou-se a hipótese de que as imagens produzidas pelas técnicas arqueométricas pudessem ser compreendidas como um fenômeno. O breve estudo sobre esta teoria levantou questões interessantes acerca da contemporaneidade, do indivíduo e seu contexto, porém, não mostra ser de aplicação direta ao tratamento da documentação abordada no contexto desta pesquisa.

Outra teoria importante sobre a atividade científica de análise e interpretação é a pragmática, uma concepção filosófica que gerou diferentes versões (JAPIASSÚ; MARCONDES, 2006). O termo foi empregado pela primeira vez em 1898, por William James (1842 - 1910) referindo-se à teoria filosófica exposta em um ensaio, em 1878, por Charles S. Peirce (1839-1914) (ABBAGNANO, 2007). O pragmatismo metodológico, também entendido como científico ou experimental, "valoriza a prática mais do que a teoria e considera que devemos dar mais importância às consequências e efeitos da ação do que a seus princípios e pressupostos" (JAPIASSÚ; MARCONDES, 2006, p.71). Nesta linha, há o pragmatismo de John Dewey (1859-1952), que empregou os termos instrumentalismo e experimentalismo para designar suas concepções pragmáticas, referindo-se a elas como "a essência do instrumentalismo pragmático" (ABBAGNANO, 2007, p.784) e explica que o conhecimento e a prática são "como um modo de agir sobre as coisas, funcionando como um instrumento constituidor de nossas experiências, por vezes, também conhecido como experimentalismo" (JAPIASSÚ; MARCONDES, 2006, p.48).

Para John Dewey, a experiência não é um 'conteúdo objetivo', mas "um objeto ou 
evento é sempre uma parte, um momento ou um aspecto especial de um mundo ambiental experimentado, isto é, de uma situação" (ABBAGNANO, 2007, p.413). No campo das artes, Dewey (2010), discute a importância da arte para a filosofia e a análise da obra de arte sob as concepções pragmáticas. Para ele "não há teste que revele com tanta segurança a parcialidade de uma filosofia quanto sua abordagem da arte e da experiência estética" (DEWEY, 2010, p. 10).

A criação artística advém do pensamento do artista, pois "o artista tem seus problemas e pensa enquanto trabalha" (DEWEY, 2010, p. 16) e a obra de arte seria, portanto, as ideias transformadas em "significados coletivos dos objetos" (DEWEY, 2010, p. 16). Este autor enfatiza a necessidade do contexto, repudiando a ideia da obra como objeto retirado de qualquer ligação com a experiência concreta, isolado ou desvinculado de outras modalidades do experimentar (DEWEY, 2010). Assim, "a arte é produto da interação contínua e cumulativa de um eu orgânico com o mundo" (KAPLAN apud DEWEY, 2010, p. 18). Seu foco é a experiência proporcionada pelo produto artístico (DEWEY, 2010), independentemente, das obras derivadas, como, por exemplo, um poema lido por diferentes pessoas, ou de uma música interpretada por diferentes intérpretes, ou apresentada em diferentes espetáculos, Dessa forma, afirma não se interessar pela distinção entre o produto artístico e a obra de arte.

As imagens geradas como resultados de técnicas de análises físicas e químicas revelam informações sobre a obra de arte que vão além da experiência sensível, proporcionando outros tipos de experiências. Podem contribuir muito para entender e reconstruir o contexto de produção do produto artístico. Por outro lado, diferenciar o que seriam as imagens originais e as imagens derivadas é crucial para o tratamento dos documentos abordados nesta pesquisa, e nesse aspecto, a teoria pragmática não fornece apoio suficiente para operacionalizar as questões desta pesquisa.
Portanto, retomamos a teoria da semiótica de Peirce (2015), organizada em três categorias fundamentais, que ele chamou a princípio de primeiridade, secundidade e terceiridade. A primeiridade é "a consciência que pode ser compreendida como um instante do tempo, consciência passiva da qualidade, sem reconhecimento ou análise" (PEIRCE, 2015, p. 14), também denominada de: oriência ou originalidade que, "tal como aquele ser é independentemente de qualquer outra coisa." (PEIRCE, 2015, p. 27).

A segunda categoria, a secundidade, é a "consciência de um fato externo ou outra coisa" (PEIRCE, 2015, p. 14), como se houvesse um "elemento que é a força bruta." (PEIRCE, 2015, p. 23). Tal brutalidade "consistirá na ausência de qualquer razão, regularidade ou norma que poderia tomar parte na ação como elemento terceiro ou mediador." (PEIRCE, 2015, p. 23). Também é denominada binariedade ou obsistência.

A terceiridade, ou transuasão, é a "consciência sintética, que reúne tempo, sentido de aprendizado, pensamento." (PEIRCE, 2015, p. 14). Ou seja, em uma ação intelectual será encontrada uma ligação tripla que requer uma mediação, da qual nasce o conceito de signo. Um signo é tudo aquilo que está relacionado com uma segunda coisa, seu Objeto, com respeito a uma qualidade, de modo tal a trazer uma terceira coisa, seu Interpretante, para uma relação com aquele Objeto (PEIRCE, 2015, p. 28)

O signo genuíno, originário da terceiridade, é um "signo cuja virtude significante se deve a um caráter que só pode ser compreendido com a ajuda de seu interpretante" (PEIRCE, 2015, p. 28-29), não precisando realmente existir, sendo suficiente a sua possibilidade de existência no futuro (PEIRCE, 2015). Peirce denomina este tipo de signo de Símbolo. Ao sofrer uma degeneração, o símbolo é denominado "signo Obsistente, ou Índice" (PEIRCE, 2015, p. 28). Este signo tem uma relação genuína 
com o seu objeto, não levando em consideração o interpretante (PEIRCE, 2015). O signo, ao passar por uma última degeneração, o índice, reduz-se à sua qualidade, passando a ser denominado de signo originaliano, ou Ícone (PEIRCE, 2015).

A imagem pode ser abordada na semiótica pelo ângulo da significação, com base na tríade significante, referente e significado.

uma fotografia (significante) que apresenta um grupo alegre de pessoas (referente) pode significar, de acordo com o contexto, 'foto de família' ou, em uma publicidade, 'alegria' ou 'convívio' (significados). (JOLY, 2012, p. 34)

Segundo Bohnsack (2007), cada significante se relaciona a um significado e este se relaciona não com o objeto real, mas com a imagem mental do referente. Ou seja, cada signo é uma representação que está no lugar do objeto real. O signo está "ali, presente, para designar ou significar outra coisa, ausente, concreta ou abstrata." (JOLY, 2012, p. 33).

A imagem como um todo pode ser um signo, pois ela representa algo que não está ali, bem como cada elemento que compõe uma imagem pode ser considerado um signo. Neste caso, o ícone "corresponde à classe de signos cujo significante mantém uma relação de analogia com o que representa, isto é, com o seu referente." (JOLY, 2012, p. 35). Ou seja, a pintura de uma árvore representa uma árvore em âmbito genérico.

O índice "corresponde à classe dos signos que mantêm uma relação causal de contiguidade física com o que representam." (JOLY, 2012, p. 35), ou seja, o signo de fumaça indica fogo. As relações estabelecidas são naturais e dedutíveis. $\mathrm{E}$, o símbolo, "corresponde à classe dos signos que mantêm uma relação de convenção com o seu referente." (JOLY, 2012, p. 36), ou seja, o seu significado é dado por convenção, por exemplo, uma pomba branca pode ser um símbolo da paz.

Segundo Santaella (1983), as imagens provenientes de máquinas como fotografias, cinema e televisão seriam signos híbridos formados de hipoícones (imagens) e de índices. Seriam considerados índices pois, para Santaella (1983), as máquinas registram o efeito de radiações partidas do objeto criando uma conexão física. Este índice, por sua vez, seria altamente informativo (SANTAELLA, 1983). Portanto, seguindo este raciocínio, as imagens produzidas pela técnica de análise arqueométrica se enquadram nesse tipo de signo, pois são imagens que registram os resultados dos efeitos das radiações eletromagnéticas de luz visível, infravermelho, ultravioleta e raio- $X$ que interagem com a obra de arte.

Para Peirce (2015), os dados de pressão baixa e ar úmido em um barômetro também são índices, pois "supomos que as forças da natureza estabelecem uma conexão provável entre o barômetro que marca pressão baixa com ar úmido e a chuva iminente." (PEIRCE, 2015, p. 67). Com este exemplo, podemos considerar que os resultados em gráficos, gerado pelas técnicas de análise elementar e composicional (RIZZUTTO, 2015), também se enquadram na categoria dos índices.

A documentação iconográfica aqui estudada pode, portanto, ser analisada segundo a semiótica peirciana, pois as imagens e os gráficos se comportam como índices, ou seja, mantêm relação genuína com a obra de arte, independentemente da relação com o interpretante (PEIRCE, 2015). Deve-se considerar também outros dados técnicos que trazem as informações necessárias para reconstituir o experimento e outras documentações adjacentes como amostras geradas, pareceres técnicos, vídeos que documentam as análises, notas, publicações utilizadas para interpretação dos resultados, ou geradas pelos resultados. 


\section{Sistema de informação e recuperação de imagens arqueométricas: requisitos}

A elaboração de sistemas de informação para recuperar documentação arqueométrica tem a finalidade de facilitar o acesso dos usuários aos dados gerados pelas pesquisas desse campo. O sistema deve abrigar informações representativas dos processos de pesquisa, que permitam discriminar e registrar os produtos obtidos (GONZALES apud RODRIGUEZ, 2002). Para tanto, é necessário dispor de meta- dados que "são os elementos ou estruturas de organização da informação que, atribuídos a cada objeto de informação eletrônica, os classificam, caracterizam ou descrevem" (RODRIGUEZ, 2002, p.21), a fim de possibilitar a pesquisa e recuperação (GILLILAND apud BACA, 2016). No exemplo abaixo, tem-se uma reprodução fotográfica de uma pintura em Negativo de Vidro. Foi produzida para ser utilizada em publicações em livros, catálogos, ou outros tipos de mídias. Trata-se, portanto, de um substituto de um original.

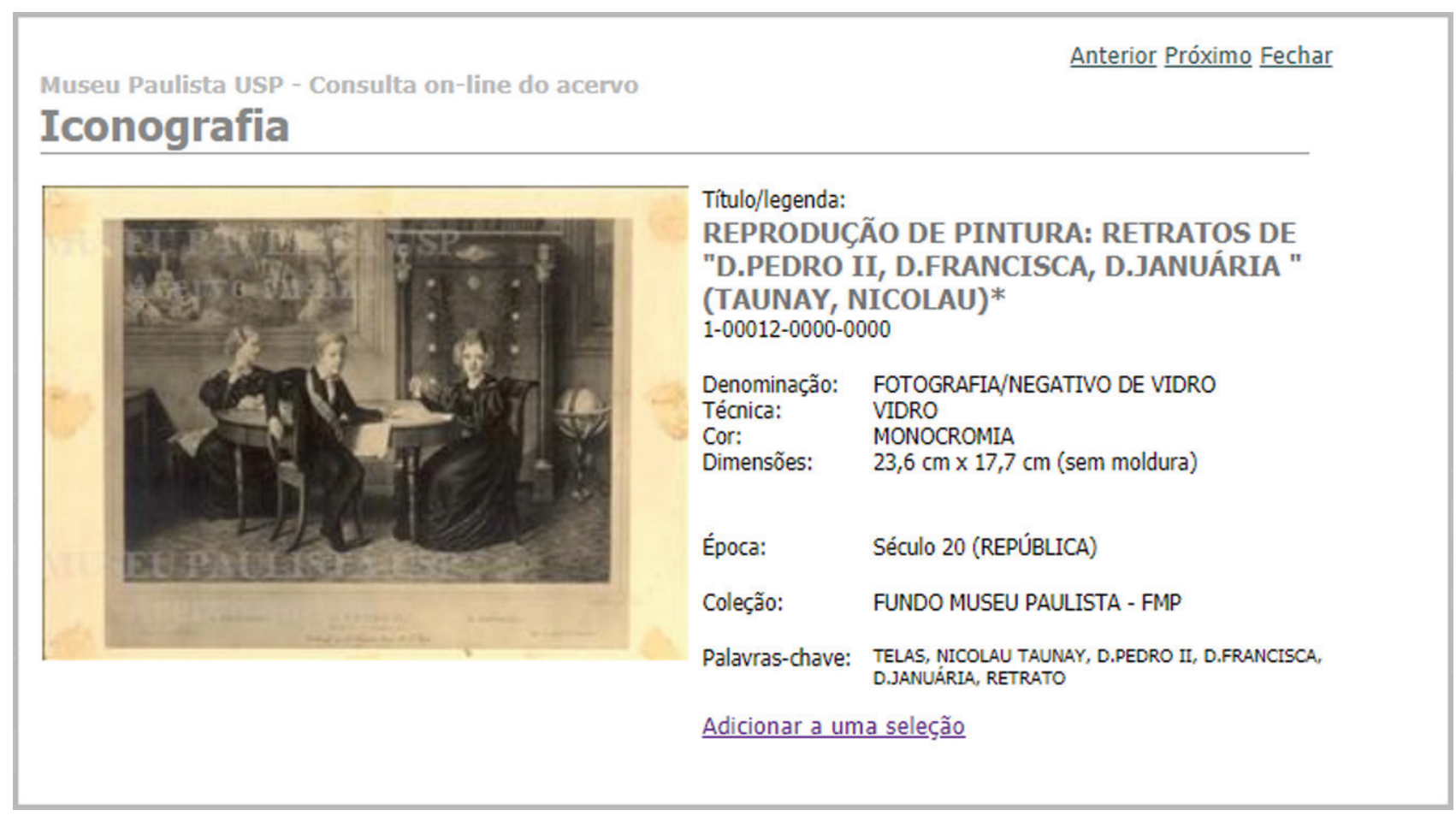

Figura 3 - Ficha catalográfica da obra Reprodução de Pintura: retratos de 'D. Pedro II, D. Francisca, D. Januária' pertencente ao Fundo Museu Paulista.

Fonte: Museu Paulista. Consulta online do acervo. Disponível em: http://www.acervo.mp.usp.br/lconografiaV2.aspx\#.

Os metadados presentes no registro do catálogo do museu paulista são de identificação (título/legenda) e descrição (Dimensão, técnica, cor, etc.). Os dados propostos no Capítulo 8 da AACR2 (2005) para materiais gráficos são: (a) título e indicação de responsabilidade; (b) edição; (c) detalhes específicos do material; (d) dados de publicação e distribuição; (e) descrição física; (f) série. (g) notas; (h) número normalizado e das modalidades de aquisição; (i) itens suplementares; (j) fac-símiles, fotocópias e outras reproduções. 
As imagens abordadas na presente pesquisa são imagens científicas, por exemplo, se fosse tirada uma fotografia de infravermelho da pintura acima, ela poderia revelar a presença de desenhos subjacentes à obra. Os mesmos campos de descrição poderiam ser atribuídos a esta imagem, porém, as imagens geradas em experimentos científicos não se enquadram nestas categorias e apresentam detalhes que vão além dos dados propostos pela AACR2 (2005). Com efeito, cada técnica gera uma imagem com características particulares, revelando informações sobre o documento que não seriam possíveis de se obter a olho nu. Além disso, um estudo pode ser realizado por meio de uma única técnica ou pela combinação de várias delas. A integração dessas análises ficaria comprometida em um sistema de informação tradicional que siga o modelo da ISBD (Descrição Bibliográfica Internacional Normalizada), em que cada análise se comportaria como um documento.

Neste caso, o modelo conceitual FRBR (Requisitos Funcionais para Registros Bibliográficos) é mais adequado para representar documentos, baseado em relações entre entidades, de modo a estabelecer relações lógicas entre eles dentro de um banco de dados (IFLA, 2009). Esse modelo fornece uma estrutura para que os dados referentes a um documento possam interagir uns com os outros, modelando novas maneiras de lidar com a informação. A estrutura do modelo é composta por 10 entidades, organizadas em três grupos, que se baseiam nos produtos do trabalho intelectual ou artístico; na disseminação da produção desse trabalho e nos conteúdos que permeiam esses trabalhos. Ou seja, "são todos os recursos, aos quais damos acesso através de um catálogo." (ZHANG; SALABA, 2009, p. 14, tradução nossa).

O grupo 1 é composto por: (a) obra, que é uma criação intelectual ou artística; (b) expressão, que é a realização da obra; (c) manifestação, que é a realização física de uma expressão; (d) item, que é o exemplar (único) de uma manifestação.
O grupo 2 por sua vez é composto pelos agentes responsáveis: (e) pessoa e (f) órgão, entidade coletiva. O grupo 3 adiciona ainda: (g) conceito; (h) objeto; (i) evento; (j) lugar (ZHANG; SALABA, 2009).

Ainda assim, as informações que circundam a documentação estudada são diferentes das comumente abordadas pelos centros de documentação, bibliotecas e museus. Por se tratar de imagens científicas, informações específicas dessa natureza devem ser preservadas. Diante desse contexto, a Curadoria Digital aponta diretrizes interessantes para a gestão dos dados de pesquisa.

Segundo Lee e Tibbo (2007), a Curadoria Digital aborda a gestão de dados desde a sua criação, no sentido de gerar novas fontes de informação e de conhecimentos. Sayão e Sales (2012) destacam a importância do acesso e recuperação desses dados no desenvolvimento de projetos científicos. É importante observar que os dados, neste contexto, não têm o mesmo sentido atribuído aos dados de bancos de dados bibliográficos.

Em um banco de dados bibliográficos, o campo de título, do autor, da editora, descrevem o documento. São dados intrínsecos à obra, podendo ser registrados a posteriori à sua produção e, portanto, só se perderiam juntamente com a perda da própria obra. No contexto da Curadoria Digital, os dados são observações ou resultados de um experimento, coletados e registrados no processo de realização da pesquisa. Segundo Amaral (2016), são fatos coletados e armazenados, além dos valores, ou conteúdo coletado, o processo, os métodos, detalhes dos instrumentos utilizados, etc. Esses registros são importantes para reproduzir o experimento, analisá-lo, ou dar continuidade, em outra época.

Amaral (2016) classifica os dados em: (a) dados estruturados, que são aqueles que possuem uma estrutura, normal- 
mente, organizados em colunas e linhas devidamente nomeadas; (b) dados semi estruturados, em que "existe uma estrutura representada, porém ela não é fixa, podendo ser alterada com a inclusão de mais dados já nesta nova configuração" (AMARAL, 2016, p. 33); (c) dados não estruturados que "muitas vezes, este tipo de dado não possui sequer qualquer tipo de metadado" (AMARAL, 2016, p. 33).

As imagens consideradas na presente pesquisa são apenas uma parte dos dados de um experimento global, que envolve outros dados que não são intrínsecos à imagem em si. Mesmo os dados estruturados não apresentam por si mesmos, a metodologia utilizada para a sua coleta, informação esta que é muito importante para a compreensão e reutilização dos dados para empregos futuros. Essas questões fazem parte das propostas de Curadoria Digital, que visam encontrar as condições necessárias para preservar os dados, compartilhá-los (ao longo do tempo e do espaço), de modo a garantir sua confiabilidade, integridade, autenticidade e proveniência.

Esta preocupação tem sido compartilhada pelas agências de fomento, nacionais e internacionais. Por exemplo, a FAPESP reconhece a importância da gestão adequada dos dados de pesquisa e inclui, em seu site, instruções aos pesquisadores que pleiteiam o financiamento de suas pesquisas. Ressalta que "considera necessário que os dados resultantes de projetos financiados pela Fundação sejam gerenciados e compartilhados de forma a garantir o maior benefício possível para o avanço científico e tecnológico" (FAPESP). Além disso, é interessante que sejam passíveis de serem citados nos registros acadêmicos e conectados às publicações que venham a utilizá-los. Para tanto, os sistemas de informação precisam incluir, segundo Sayão e Sales (2012), três ações para o ciclo de vida dos dados de pesquisa: 1) ações para todo o ciclo de vida; 2) ações sequenciais; 3) ações ocasionais.
Com o item 1, ações para todo o ciclo de vida, tem-se "uma ideia de presença contínua, essas ações estão representadas graficamente como anéis concêntricos envolvendo os dados que estão no centro do modelo" (SAYÃO; SALES, 2012, p. 185) para promover:

1. Descrição e representação da informação: é efetivada pela atribuição de metadados administrativos, técnicos, estruturais e de representação de acordo com os padrões apropriados; visa assegurar a descrição adequada e o controle de longo prazo; compreende também a coleta e a atribuição de informações de representação necessárias para o entendimento do dado e para a sua apresentação (ou renderização) (SAYÃO; SALES, 2012, p. 185);

2. Planejamento da Preservação: é necessário definir um plano de preservação cujo espectro englobe todo o ciclo de vida da curadoria do material digital, incluindo gestão, administração, políticas e tecnologias (SAYÃO; SALES, 2012, p. 185);

3. Participação e monitoramento: enfatiza a necessidade de atenção para as atividades que se desenrolam no âmbito das comunidades envolvidas com o problema de curadoria, bem como a necessidade de participação no desenvolvimento de padrões, de ferramentas e de software adequados ao problema e que possam também serem compartilhados (SAYÃO; SALES, 2012, p. 185);

4. Curadoria e preservação: estar continuamente alerta e empreender as ações administrativas e gerenciais planejadas para a curadoria e preservação por todo o ciclo de vida da curadoria (SAYÃO; SALES, 2012, p. 186).

No item 2, ações sequenciais, temos as "etapas que devem ser cumpridas repetidamente para assegurar que o dado permaneça em contínuo processo 
de curadoria" (SAYÃO; SALES, 2012, p. 186), sendo elas de:

- Conceitualização: "conceber e planejar a criação do dado, incluindo os métodos de captura e as opções de armazenamento" (SAYÃO; SALES, 2012, p. 127); questões tais como propriedade intelectual, embargos e restrições, financiamento, responsabilidades, objetivos específicos da pesquisa, ferramentas de captura e calibração devem ser registradas;

- Criação e/ou Recebimento: compreende a criação do "dado incluindo o elenco de metadados necessários à sua gestão e compreensão, ou seja, metadados administrativos, descritivos, estruturais e técnicos; os metadados de preservação também podem ser incluídos no momento da criação do dado." (SAYÃO; SALES, 2012, p. 127);

- Avaliação e seleção: "avaliar o dado e selecionar o que será objeto dos processos de curadoria e de preservação por longo prazo" (SAYÃO; SALES, 2012, p. 127);

- Capturar: "transferir o dado para um arquivo, repositório, centro de dados ou outro custodiante apropriado" (SAYÃO; SALES, 2012, p. 127);

- Ações de preservação: são ações para "assegurar a preservação de longo prazo e a retenção do dado de natureza oficial" (SAYÃO; SALES, 2012, p. 127); devem assegurar a autenticidade, a confiabilidade e integridade dos dados, que inclui "a limpeza do dado e a sua validação, a adição de metadados de preservação e de informação de representação e a garantia de estruturas de dados ou formatos de arquivos aceitáveis" (SAYÃO; SALES, 2012, p. 127);

- Armazenamento: "armazenar o dado de forma segura mantendo a aderência aos padrões relevantes" (SAYÃO; SALES, 2012, p. 127);
- Acesso, uso e reuso: garantir que o dado possa ser "cotidianamente acessado tanto pela sua comunidade alvo quanto pelos demais usuários interessados no reuso do dado" (SAYÃO; SALES, 2012, p. 128);

- Transformação: "criar novos dados a partir do original" (SAYÃO; SALES, 2012, p.128).

As ações sobre o ciclo de vida dos dados, expostas pela Curadoria Digital, contribuíram para organizar o desenvolvimento da pesquisa. Permitiu rever conceitos e ter uma melhor compreensão dos metadados. Ou seja, os metadados possuem, segundo Rodriguez (2002), as funções de: a) identificação e descrição da informação; b) busca e recuperação; c) localização e formas de acesso; d) atualização da informação; e) preservação e conservação; f) limitação de uso; g) valorização do conteúdo; h) visibilidade da informação; i) acessibilidade ao conteúdo.

E especulou-se, também, sobre alguns modelos de metadados como o de Burnett, Bor Ng e Park (1999 apud RODRIGUEZ, 2002) que separam os metadados em dois grupos: os intrínsecos e extrínsecos. O primeiro apresenta as características inerentes ao objeto de informação como título, autor, etc., e, o segundo, as características vinculadas ao sistema como, modo de acesso, controle, etc.

Hill et al (1999 apud RODRIGUEZ, 2002) também separam em dois grupos, chamando-os de inerentes e contextuais, voltados para informações de "análises informáticas do conteúdo" (RODRIGUEZ, 2002, p. 59) e de "informação que não se pode extrair diretamente dos conteúdos da coleção" (RODRIGUEZ, 2002, p. 59). Os modelos de dois grupos pareceram desde o princípio insuficientes às necessidades apresentadas pela pesquisa. Ao analisar o modelo de ciclo de vida dos dados, proposto pela Curadoria Digital, confirmou 
que os modelos de dois grupos realmente não atendem às demandas.

\section{Prothman (2000 apud RODRIGUEZ,} 2002) divide os metadados em cinco categorias específicas: 1) Metadados de acesso; 2) Metadados semânticos; 3) Metadados de qualidade (informação que permitem análises qualitativas dos dados); 4) Metadados de transferência (informam como os dados podem transferir-se entre aplicações); 5) Metadados de armazenamento.

Gilliand (2016) também propõe cinco categorias de metadados que chama de: 1) administrativos, cujos metadados gerenciam os objetos de informação como, por exemplo, informação de aquisição, protocolos legais, protocolos de acesso, localização etc.; 2) descritivos, que descrevem os objetos de informação tanto com dados do sistema, como pelos dados catalográficos e outras informações da instituição, como informações curatoriais, anotações, emen- das etc.; 3) de preservação, se ocupam da gestão de preservação indicando condição física, ações de preservação físicas e digitais (atualização e migração de dados); 4) técnicos, composto de metadados sobre o funcionamento do sistema (hardware e software), onde entram também as informações de digitalização técnica (por exemplo, formatos, relações de compressão, rotinas de escala), de autenticação e segurança (senhas); 5) de uso, dados que especificam os níveis e tipos de uso dos objetos de informação como, por exemplo, registros de circulação, uso de usuários etc.

Dentre os modelos propostos, a divisão de Gilliand (2016), é a que mais se adéqua às necessidades de instituições que lidam com obras do patrimônio cultural porque permite a inserção dos dados necessários à descrição das técnicas de análise arqueométrica ao ciclo de vida dos dados de pesquisa. Propõe-se, nessa perspectiva, a seguinte organização:

\begin{tabular}{|c|c|c|}
\hline Tipos de Metadados & Aplicação & Campo (termos) \\
\hline Administrativos & $\begin{array}{l}\text { Metadados que gerenciam os objetos de informação; protocolos } \\
\text { legais; protocolos de acesso; localização }\end{array}$ & $\begin{array}{l}\text { A. dados da obra } \\
\text { B. indicação de responsabilidade } \\
\text { C. data de análise } \\
\text { D. protocolos legais; } \\
\text { E. protocolos de acesso; } \\
\text { F. localização }\end{array}$ \\
\hline Descritivos & Metadados que descrevem o objeto de informação & $\begin{array}{l}\text { A. tipo de análise } \\
\text { B. nome da técnica } \\
\text { C. tipo de documento iconográfico } \\
\text { D. informação revelada } \\
\text { E. documentação adicional } \\
\text { F. relatório técnico }\end{array}$ \\
\hline Preservação & $\begin{array}{l}\text { Metadados sobre a gestão de preservação; indicações de ações fisicas } \\
\text { e digitais (atualização e migração) }\end{array}$ & A. dados do sistema \\
\hline Téenicos & Metadados sobre o funcionamento do sistema (hardware e software) & A. condições experimentais \\
\hline Acesso & Metadados que especificam os níveis e tipos de acesso & A. classificação de acesso \\
\hline
\end{tabular}

Tabela 1: Organização da estrutura de metadados para documentação iconográfica de técnicas de análises arqueométricas, com base em Gilliland (2016). 
Observa-se também que algumas informações são de caráter sensível e não devem ser de acesso aberto ao público por questões de segurança da obra. A privacidade do cientista/pesquisador também deve ser considerada sem ser confundida com o seu monopólio.

\section{Considerações finais}

Tendo em vista o objetivo desta pesquisa, de buscar fundamentos teóricos e metodológicos de tratamento informacional de imagens e gráficos gerados por meio de análises físico-químicas, pode-se constatar, por meio da revisão de literatura, que eles devem ser tomados como dados de pesquisa não estruturados, o que requer o registro das informações pertinentes no banco de dados no ato de sua elaboração. Por isso, é de extrema importância a constituição de um repositório apto a armazenar essa documentação.

Ao analisar os modelos de representação bibliográfica, observou-se que os metadados bibliográficos não atendiam à demanda que a documentação arqueométrica exige. Encontrou-se um modelo mais satisfatório na proposta de Gilliand (2016): 1) administrativos; 2) descritivos; 3) de preservação; 4) técnicos; 5) de uso.

Como bem destacam Sayão e Sales (2012), ainda existe a mentalidade, por parte de alguns pesquisadores, de que os dados gerados na pesquisa são de sua propriedade. Porém, deve-se observar que as pesquisas são, geralmente, produzidas com financiamentos públicos $\mathrm{e}$, portanto, são um bem público. Os repositórios devem não só armazenar e disponibilizar os dados de forma adequada, mas também apresentar a flexibilidade necessária para garantir a privacidade e segurança dos dados e do pesquisador, para que não venham a prejudicar a possibilidade de obtenção de patentes, aplicações comer- ciais, segurança ou ainda pela necessidade de anonimização. Mesmo os dados que não podem ser compartilhados, em um primeiro momento, precisam ser preservados e geridos para usos futuros.

Mas quando se pensa em um futuro constituído de décadas, o meio digital coloca um duplo desafio. Se, por um lado, ela permite "criar, manipular, armazenar e tornar disponível uma quantidade impressionante de informações, por outro lado, esta mesma tecnologia fugidia coloca em perigo a longevidade dos objetos informacionais por ela engendrada" (SAYÃO; SALES, 2012, p. 188-189). A preservação digital é, portanto, um problema que surge na contemporaneidade e que deve ser levada em conta desde o início da elaboração de projetos de repositórios digitais de dados de pesquisa.

\section{Referências}

AACR2. Código de catalogação anglo-americano. São Paulo: FEBAB; Imprensa Oficial do Estado de São Paulo, 2005.

ABBAGNANO, Nicola. Dicionário de Filosofia. São Paulo: Martins Fontes, 2007.

AMARAL, Fernando. Introdução a ciência de dados: mineração de dados e Big Data. Rio de Janeiro: Alta Books, 2016.

ARQUIVO NACIONAL. Dicionário brasileiro de terminologia arquivística. Rio de Janeiro: Arquivo Nacional, 2005.

BACA, Murtha. Introduction to art image access: issues, tools, standards, strategies. Los Angeles : Getty Research Institute, 2002.

BERNARDES, leda Pimenta et al. Gestão documental Aplicada. São Paulo: Arquivo Público do Estado de São Paulo, 2008. 
BOHNSACK, Ralf. A interpretação de imagens e o Método Documentário. Sociologias, Porto Alegre, ano $9, n^{\circ} 18$, p. 286-311, jun./dez. 2007.

DARTIGUES, André. O que é fenomenologia. São Paulo: Editora Brasiliense, 1992.

DEWEY, John. Arte como experiência. São Paulo: Martins Fontes, 2010.

FAPESP. Plano de Gestão de Dados. Disponível em: http://www.fapesp.br/gestaodedados/. Acesso em: 02 dez. 2018.

FARIA, Maria Isabel; PERICÃO, Maria da Graça. Dicionário do livro: da escrita ao livro eletrônico. São Paulo: EDUSP, 2008.

GILLIAND, Anne J. Setting the Stage. In: BACA, Murtha. Introduction to metadata. Los Angeles: Getty Research Institute, 2016. Disponível em: http://www.getty.edu/publications/intrometadata/ introduction/.

GUINCHAT, Claire; MENOU, Michel. Introdução geral às ciências e técnicas da informação e documentação. Brasília: IBICT, 1994.

IFLA. Functional Requirements for Bibliographic Records: final reports. International Federation of Library Associations and Institutions, 2009. Disponível em: https://www.ifla.org/files/assets/cataloguing/frbr/frbr_2008.pdf. Acesso em: 16 dez. 2018.

JAPIASSÚ, Hilton; MARCONDES, Danilo. Dicionário básico de filosofia. Rio de Janeiro, RJ : Jorge Zahar, 2006.

LAMFI - Laboratório de Análises de Materiais Por Feixes lônicos do Instituto de Física da Universidade de São Paulo. Relatório de Atividades 2004-2009. São Paulo, 2009. Disponível em:<http://www2.if.usp. br/ lamfi/Relat2009.pdf>. Acesso em: 17 maio 2017.

MERLEAU-PONTY, Maurice; BANNAN, John F. What is phenomenology? CrossCurrents, Vol. 6, No. 1 (WINTER 1956), pp. 59-70. Disponível em: http://www.jstor.org/stable/24456652. Acesso em: 31 out. 2017.

MOLEIRO, Guilherme F; PASCHOLATI, Paulo R; RIZZUTTO, Márcia A. Uso da técnica PIXE em obras e objetos do pintor Almeida Júnior. Instituto de Física, Universidade de São Paulo. s/d.

NAP-FAEPAH. Núcleo de Apoio à Pesquisa de Física Aplicada ao Estudo do Patrimônio Artísti- co e Histórico. Disponível em: http://www.usp.br/ faepah/?q=pt-br. Acesso em: 11 set. 2016.

PANOFSKY, Erwin. Studies in Iconology: Humanist Themes in the Art of the Renaissance. New York: Oxford University Press, 1939.

PINHEIRO, Lena Vania Ribeiro; FERREZ, Helena Dodd. Tesauro Brasileiro de Ciência da Informação. Rio de Janeiro; Brasília: Instituto Brasileiro de Informação em Ciência e Tecnologia (Ibict), 2014.

RIZZUTTO, Márcia A. Análises não-destrutivas em obras de arte com técnicas atômico-nucleares. Revista CPC, São Paulo, n. 6, p. 208-218, maio-out. 2008.

RIZZUTTO, Márcia A. et al. Analytical techniques applied to study cultural heritage objects. INAC 2015: international nuclear atlantic conference Brazilian nuclear program State policy for a sustainable world. Brazil, 2015.

RIZZUTTO, Márcia A.; KAJIYA, Elizabeth; CAMPOS, Pedro H. O. V. Arqueometria: Ciência à Serviço da Arte: Técnicas não Destrutivas de Análise da Pintura. Disponível em: http://museu.ccsl.ime. usp.br/tecnicas/.

RODRIGUEZ, Eva Méndez. Metadatos y recuperación de información: estándares, problemas y aplicabilidad en bibliotecas digitales. Gijón: Trea, 2002.

SAYÃO, Luis Fernando; SALES, Luana Farias. Curadoria Digital: um novo patamar para preservação de dados digitais de pesquisa. Inf. \& Soc.:Est., João Pessoa, v.22, n.3, p. 179-191, set./dez. 2012.

SMIT, Johanna W. Documentação audiovisual. In: BELLOTTO, H.L.; LIMA, Y.D.; SMIT, J.W. (coord.) Organização de arquivos. São Paulo: ECA/ IEB, 2000.

TABACNIKS, Manfredo H. Análise de filmes finos por pixe e rbs. São Paulo: Instituto de Física, Universidade de São Paulo, s/d.

ZHANG, Yin; SALABA, Athena. Implementing FRBR in libraries: key issues and future directions. Nova lorque: Neal-Schuman, 2009. 